\title{
Strategies for the Prevention of Invasive Fungal Infections after Lung Transplant
}

\author{
Roni Bitterman, Tina Marinelli and Shahid Husain *
}

check for

updates

Citation: Bitterman, R.; Marinelli, T.;

Husain, S. Strategies for the

Prevention of Invasive Fungal

Infections after Lung Transplant. J. Fungi

2021, 7, 122. https://doi.org/

10.3390/jof7020122

Academic Editor: Marisa H. Miceli

Received: 5 January 2021

Accepted: 4 February 2021

Published: 7 February 202

Publisher's Note: MDPI stays neutral with regard to jurisdictional claims in published maps and institutional affiliations.

Copyright: (c) 2021 by the authors. Licensee MDPI, Basel, Switzerland. This article is an open access article distributed under the terms and conditions of the Creative Commons Attribution (CC BY) license (https:// creativecommons.org/licenses/by/ $4.0 /)$.
Transplant Infectious Diseases, Ajmera Transplant Center, University Health Network, University of Toronto, Toronto, ON M5G 2C4, Canada; roni.bitterman@uhn.ca (R.B.); tina.marinelli2@uhn.ca (T.M.)

* Correspondence: shahid.husain@uhn.ca; Tel.: +1-41-6340-4800 (ext. 3144); Fax: +1-41-6340-5442

\begin{abstract}
Long-term survival after lung transplantation is lower than that associated with other transplanted organs. Infectious complications, most importantly invasive fungal infections, have detrimental effects and are a major cause of morbidity and mortality in this population. Candida infections predominate in the early post-transplant period, whereas invasive mold infections, usually those related to Aspergillus, are most common later on. This review summarizes the epidemiology and risk factors for invasive fungal diseases in lung transplant recipients, as well as the current evidence on preventive measures. These measures include universal prophylaxis, targeted prophylaxis, and preemptive treatment. Although there is consensus that a preventive strategy should be implemented, current data show no superiority of one preventive measure over another. Data are also lacking regarding the optimal antifungal regimen and the duration of treatment. As all current recommendations are based on observational, single-center, single-arm studies, it is necessary that this longstanding debate is settled with a multicenter randomized controlled trial.
\end{abstract}

Keywords: lung transplantation; invasive fungal disease; invasive aspergillosis; prophylaxis; preemptive treatment

\section{Epidemiology}

Despite advances in donor selection, surgical techniques, and immunosuppressive regimens, long-term survival after lung transplantation has only slightly improved throughout the last two decades, and the 5-year survival post-transplant is still around 50\%-60\% [1]. Invasive fungal diseases (IFDs) significantly contribute to the mortality seen among lung transplant recipients (LTRs) [2-5]. In a single-center study in the US, IFD was identified as the strongest predictor for mortality in these patients [6]. However, studies differ in terms of the time points reported for mortality and the definition of IFD used (some reporting on all IFDs, some on invasive mold diseases (IMDs), and some on invasive aspergillosis only). They all have a high mortality rate in common, ranging from $21.7 \%$ three months after the diagnosis of IFD to $58 \%$ two years after the diagnosis [2,4].

LTRs are especially prone to fungal infections due to the combination of intense immune suppression, continuous exposure of the transplanted organ to the environment, a depressed cough reflex, and airway anatomical abnormalities. The Transplant Infection Surveillance Network (TRANSNET) reported that among data collected from 11 US transplant centers between 2001 and 2006, 8.6\% of LTRs in the first year post-transplant developed an IFD. Most of these infections were IMDs (5.5\%), most commonly, invasive aspergillosis [4,7]. Other studies differ in the duration of follow-up and the fungal infection reported on; however, more extensive series reported an IMD rate of 5.4-9\% [2,5,8,9]. In the immediate postoperative period (up to 30 days), Candida infections predominate, whereas later on, mold infections are more common [7,10]. Aside from Aspergillus, which is undoubtedly the most common mold isolated, other molds include zygomycetes, Scedosporium, and dematiaceous molds, and the incidence varies between studies [4,11]. 
Most studies focused on IFD in the first 6-12 months post-transplant, as this was thought to be the most vulnerable time window [7,9]. Recently, there have been studies emphasizing the importance of late-onset IFDs. A study conducted in Ontario, Canada, demonstrated that among 942 LTRs between 2002 and 2016, the median time to the first diagnosis of IFD was 1.5 years. In that study, there was a 7.4\% incidence of IFD in the first year post-transplant and a $17.2 \%$ cumulative prevalence of IFD [3]. Another study from Toronto showed that among 350 LTRs that survived beyond the first year post-transplant, $9 \%$ developed invasive aspergillosis in the second to fourth-year post-transplant [5]. NonAspergillus molds, most notably Scedosporium spp. and zygomycetes, tend to appear later in the post-transplant course and are associated with a worse prognosis than invasive aspergillosis [12].

\section{Risk Factors}

Invasive mold infections are primarily acquired via the inhalation of fungal spores and conidia. On the one hand, the transplanted allograft has continuous contact with the environment and fungal elements of ubiquitous fungi, such as Aspergillus. On the other hand, LTRs have an impaired cough reflex and impaired mucociliary clearance due to the surgery. This combination puts LTRs at an exceptionally high risk for IMD. Numerous studies have evaluated risk factors for IFD and IMD among LTRs, with most of them being single-center studies. Amongst all risk factors, it seems that post-transplant fungal colonization is the most potent risk factor for IMD, as shown in several small single-center studies demonstrating an odds ratio (OR) of 6.69-22.4 for invasive aspergillosis [13-15]. A more significant multi-center cohort comprising 900 LTRs revealed a more modest association between 1-year post-transplant Aspergillus colonization and invasive disease, with an OR of 2.11 (95\% CI 1.28-3.49) [16]. Pre-transplant Aspergillus colonization, a single-lung transplant, rejection and augmented immune suppression, age, ischemia time, early airway ischemia, daclizumab induction treatment, re-transplant, diabetes, renal replacement treatment, the performance status, CMV infection, and hypogammaglobulinemia have been inconsistently shown to be associated with an increased risk for IMD in single-center studies $[2,8,17-20]$. However, a large multicenter study found, using a multivariate analysis, that only a single-lung transplant (OR 1.84, 95\% CI 1.09-3.1) and Aspergillus colonization less than one-year post-transplant (OR $2.11,95 \%$ CI $1.28-3.49$ ) were significantly associated with invasive aspergillosis [16]. Cystic fibrosis seems to have a strong association with IMD, mainly through pre- and post-transplant Aspergillus colonization. Several studies demonstrate high tracheobronchial aspergillosis rates and invasive aspergillosis in these patients [21-23].

\section{Diagnosis}

The ISHLT guidelines define fungal colonization as the presence of fungus in respiratory secretions identified by a culture, polymerase chain reaction (PCR), or biomarker in the absence of symptoms, and radiological and endobronchial changes [19]. Identifying fungal growth in a respiratory culture is still regarded as the gold standard for diagnosing fungal infection. It has the advantage of allowing the performance of susceptibility testing and identifying non-Aspergillus molds that would not be identified otherwise. On the other hand, the sensitivity is only approximately $50 \%$ [24,25], limiting its usefulness. Other diagnostic methods, mainly PCR and fungal biomarkers, offer an improved sensitivity when combined with a culture and address the limitations of conventional culture methods. The use of PCR is hampered by the lack of standardization between the different tests. However, a meta-analysis, mostly including patients with hematological malignancies, demonstrated a pooled sensitivity and specificity rate of $90.2 \%$ and $96.4 \%$, respectively, for Aspergillus PCR in bronchoalveolar lavage (BAL) [26]. Of the available fungal biomarkers, galactomannan is the one most widely used. The Platelia galactomannan enzyme immunoassay is the only test used worldwide and is thus highly standardized. The test identifies carbohydrate residues in the Aspergillus cell wall. As galactomannan is also 
present in the cell wall of Fusarium, Histoplasma, Blastomyces, and Penicillium, there can be false positives [27]. Serum galactomannan should not be used in LTRs due to its poor performance. A meta-analysis revealed a pooled sensitivity rate of $22 \%$ for proven invasive aspergillosis and $41 \%$ for probable invasive aspergillosis in the solid organ transplant population [28]. BAL galactomannan testing has a far better diagnostic value, with sensitivity rates ranging from $60 \%$ to $82 \%$ in the solid organ transplant population $[29,30]$. BAL galactomannan can also be assessed using a lateral flow assay, shortening the turnaround time considerably. In a study including 38 solid organ transplant patients, most of whom were LTRs, the test's sensitivity and specificity, using a 1 optical density index as the cutoff, were $100 \%$ and $42 \%$, respectively. Increasing the cutoff to a 1.5 optical density index yielded a sensitivity and specificity of $78 \%$ and $67 \%$, respectively, demonstrating results that are more comparable to the diagnostic values among patients with hematological malignancies [31]. (1-3)- $\beta$-D-glucan is a cell wall component in most fungi, except for zygomycetes, which do not produce it, and Cryptococcus, which only produces a small amount. It is thus very non-specific, as shown in two studies evaluating (1-3)- $\beta$-D-glucan in serum [32] and BAL [33] among LTRs for the diagnosis of invasive aspergillosis. The first study demonstrated a specificity of $9 \%$ for serum (1-3)- $\beta$-D-glucan when using a per-patient analysis and 59\% in a per-test analysis [32]. The study evaluating BAL (1-3)- $\beta$-D-glucan also exhibited a low specificity ranging from 53 to $70 \%$, depending on the cutoff used [33]. Due to this low to moderate specificity, (1-3)- $\beta$-D-glucan is not usually used for diagnosing fungal infections in LTRs.

\section{Prevention Strategies}

\subsection{Definitions of Prophylaxis Strategies}

In their 2015 guidelines for fungal infections in cardiothoracic transplant recipients, The International Society for Heart and Lung Transplantation (ISHLT) defines the three strategies used to prevent fungal infections in this population [19]. Universal antifungal prophylaxis refers to administering antifungal treatment for all LTRs before the isolation of a fungal pathogen in the postoperative period. Targeted prophylaxis refers to the administration of antifungal treatment in the postoperative period before there is a fungal pathogen isolated in the postoperative period, but only to LTRs at high risk of fungal infection (e.g., pre-transplant fungal colonization, cystic fibrosis, etc.). Preemptive treatment refers to only administering antifungal treatment in the postoperative period to LTRs with fungal colonization and without evidence of IFD (Figure 1).

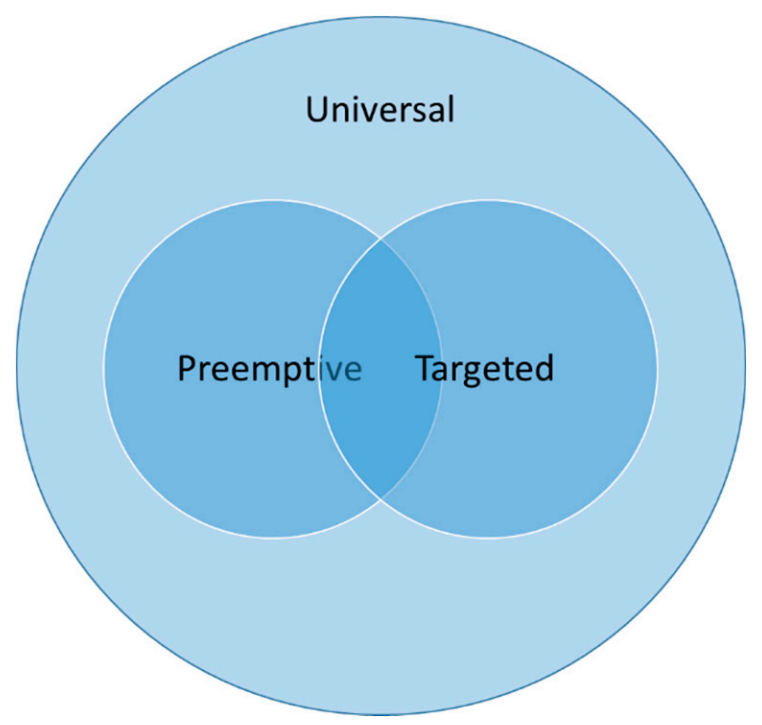

Figure 1. Invasive fungal disease prevention strategies employed in lung transplant recipients. 


\subsection{Current Practice and Recommendations}

In recent years, it seems that more transplant centers have been using prophylaxis strategies over preemptive treatment. Pennington et al. conducted a retrospective study based on administrative claims data of commercial and Medicare Advantage enrollees in the US, and found that in the years 2005-2007, the ratio of LTRs receiving prophylaxis to those not receiving it was 0.99 , and in the years 2015-2018, the ratio was 1.99 [34]. A multinational survey from 2009 included data from 58 centers worldwide and showed that $58.6 \%$ of centers implement a strategy of universal prophylaxis [35] compared to $78 \%$ in a survey of 27 US centers from 2013 [36]. It was also demonstrated that, whereas earlier surveys showed that the most common antifungals were nebulized amphotericin B deoxycholate (nAmBd) and itraconazole [37], more recent surveys demonstrate an increased use of nebulized liposomal preparations of amphotericin B and voriconazole [35,36]. In recent years, there have also been publications on the use of isavuconazole and posaconazole $[38,39]$. The duration of prophylaxis varied greatly between centers, ranging from less than three months to more than one year (and probably lifelong) [36]; however, it seems that most centers use prophylaxis for up to six months [35].

The Infectious Diseases Society of America (IDSA), the Europeans Society of Clinical Microbiology and Infectious Diseases (ESCMID), the American Society of Transplantation (AST), and the ISHLT have all recently issued guidelines addressing the prevention of fungal infections in LTRs. The AST [40] and ISHLT [19] guidelines, published in 2019 and 2016, respectively, both provide the option of using either universal prophylaxis or preemptive treatment, acknowledging that the quality of evidence is low. They recommend using either $\mathrm{nAmB}$ or a mold-active azole for universal prophylaxis, but only a moldactive azole for preemptive treatment. Suggested treatment durations are 4-6 months for prophylaxis and 3-4 months for preemptive treatment. The IDSA guidelines [27] published in 2016 and the ESCMID guidelines [41] published in 2018 both recommend universal prophylaxis as the preferred method for preventing IFD. IDSA guidelines recommend prophylaxis with either $\mathrm{nAmB}$ or a mold-active azole for 3-4 months post-transplant. They also recommend reinitiating prophylaxis during periods of augmented immune suppression. For patients with either pre- or post-transplant mold colonization, molds in the explanted lung, or a single-lung transplant, it is recommended that only mold-active azoles are applied [27].

\subsection{Current Data on Prevention Strategies}

We performed a comprehensive search of the literature using Medline database from inception to December 2020 and identified 28 studies evaluating different strategies for preventing fungal disease in LTRs (Table 1). Fifteen studies were single-arm studies assessing universal prophylaxis (10 studies) [42-51], universal and targeted prophylaxis (2 studies) [8,52], preemptive treatment and targeted prophylaxis (2 studies) [53,54], and no preventive strategy (1 study) [55]. Thirteen studies were comparative, comparing universal prophylaxis with no preventive strategy (5 studies) [34,56-59], universal prophylaxis with preemptive treatment (2 studies) $[13,16]$, universal prophylaxis with targeted prophylaxis (2 studies) [10,60], and different drugs for universal prophylaxis (4 studies) [38,61-63]. Only one study was a randomized controlled trial [61], whereas all the others were observational trials. The studies identified included data from the years 1990 to 2017. The duration of antifungal prophylaxis and/or treatment ranged from only during the transplant-associated hospitalization to lifelong antifungal prophylaxis. The duration of follow-up varied from two months to 60 months. All studies reported on either IFD or invasive aspergillosis; however, only 13 studies reported fungal colonization and mortality. 
Table 1. Studies evaluating preventive strategies for fungal disease in lung transplant recipients.

\begin{tabular}{|c|c|c|c|c|c|c|c|c|c|c|}
\hline Study & Years & $\mathbf{N}$ & Strategy & Antifungal & $\begin{array}{l}\text { Duration of } \\
\text { Prophylaxis, } \mathrm{m}\end{array}$ & $\begin{array}{l}\text { Duration of } \\
\text { Follow-up, m }\end{array}$ & IFD & IA & $\begin{array}{l}\text { Colonization } \\
\text { (As- } \\
\text { pergillus/mold) }\end{array}$ & Mortality \\
\hline \multicolumn{11}{|c|}{ Non-comparative studies } \\
\hline $\begin{array}{l}\text { Hamacher } \\
1999\end{array}$ & 1993-1997 & 31 & $\begin{array}{c}\text { Preemptive }+ \\
\text { targeted }\end{array}$ & Itraconazole & 4.2 , mean & 19.4, mean & $3(9.6 \%)$ & $2(6.4 \%)$ & & $8(25.8 \%)$ \\
\hline Palmer 2001 & 1997-1998 & 51 & Universal & nABLC & 2 & $12 \sim$ & 6 & 0 & & \\
\hline Shitrit 2005 & 1994-2004 & 40 & Universal & Itraconazole & 6 & 12 & $2(5 \%)$ & $2(5 \%)$ & $11(27.5 \%)$ & \\
\hline Lowry 2007 & $2002-2004$ & 38 & Universal & $\mathrm{nAmBd} / \mathrm{nLAmB}$ & 0.25, median & NS & $1(2.6 \%)$ & $1(2.6 \%)$ & 0 & \\
\hline Borro 2008 & 2005-2007 & 60 & Universal & nABLC + fluconazole & $\begin{array}{c}\text { nABLC-3m } \\
\text { fluconazole-3w }\end{array}$ & 6 & 0 & 0 & $1(0.15 \%)$ & \\
\hline Eriksson 2010 & 2002-2010 & 76 & $\begin{array}{l}\text { Universal + } \\
\text { targeted }\end{array}$ & $\begin{array}{l}\text { Universal-nAmBd/nABLB } \\
\text { Targeted-caspofungin }\end{array}$ & $\begin{array}{c}\text { Universal-till } \\
\text { anastomosis heals } \\
\text { Targeted-not specified }\end{array}$ & 31.2, median & $3(3.9 \%)$ & $3(3.9 \%)$ & $12(15.7 \%)$ & $11(14.5 \%)$ \\
\hline Hayes 2011 & 2001-2005 & 41 & Universal & Itraconazole & 12, median & Varied, at least 12 & $8(19.5 \%)$ & $6(14.6 \%)$ & & $32 \%{ }^{@} 3 y$ \\
\hline Pinney 2011 & 1994-2006 & 242 & None & & & 34, median & $22(9 \%)$ & $11(4.5 \%)$ & & $44 \%{ }^{@} 3 y$ \\
\hline Neoh 2013 & NS & 62 & Preemptive & Voriconazole & 3, median & 12 & $1(1.6 \%)$ & $1(1.6 \%)$ & & $16(25.8 \%)$ \\
\hline Kato 2014 & 2008-2012 & 30 & Universal & Itraconazole $^{\sim}$ & Variable, at least 12 & $60^{\sim}$ & $5(16.6 \%)$ & $5(16.6 \%)$ & & \\
\hline Chong 2015 & 2002-2011 & 91 & Universal & Voriconazole/itraconazole & $\begin{array}{l}\text { At least } 12 \text { (most } \\
\text { lifelong) }\end{array}$ & $\begin{array}{c}\text { Variable, at least } \\
12\end{array}$ & $15(16.5 \%)$ & $10(10.9 \%)$ & $27(29.6 \%)$ & $\begin{array}{l}15.3 \% @ 1 y \\
49.4 \%{ }^{\circledR} 3 y\end{array}$ \\
\hline Peghin 2016 & 2003-2013 & 412 & Universal & nLAmB & Lifelong & 30.7 , mean & $22(5.3 \%)$ & $22(5.3 \%)$ & $61(14.8 \%)$ & \\
\hline Stelzer 2018 & $2014-2016$ & 9 & Universal & Posaconazole & At least 6 & 15, median & 0 & 0 & $2(22.2 \%)$ & \\
\hline Baker 2020 & 2007-2014 & 815 & Targeted * & $\begin{array}{c}\text { Universal-nABLC } \\
\text { Targeted-mold-active } \\
\text { azole/micafungin/nABLC }\end{array}$ & $\begin{array}{l}\text { Universal-till discharge } \\
\text { Targeted-variable }\end{array}$ & 3 & $156(19.1 \%)$ & $42(5.1 \%)$ & & \\
\hline \multicolumn{11}{|c|}{ Comparative studies } \\
\hline \multirow{2}{*}{ Calvo 1999} & \multirow{2}{*}{ 1990-1997 } & 52 & Universal & nAmBd + fluconazole & $\begin{array}{l}\text { Till discharge } \\
\text { 1.4, mean }\end{array}$ & \multirow{2}{*}{$\begin{array}{c}\text { During } \\
\text { hospitalization }\end{array}$} & 0 & 0 & & \\
\hline & & 13 & None & & & & $3(23 \%)$ & NS & & \\
\hline
\end{tabular}


Table 1. Cont.

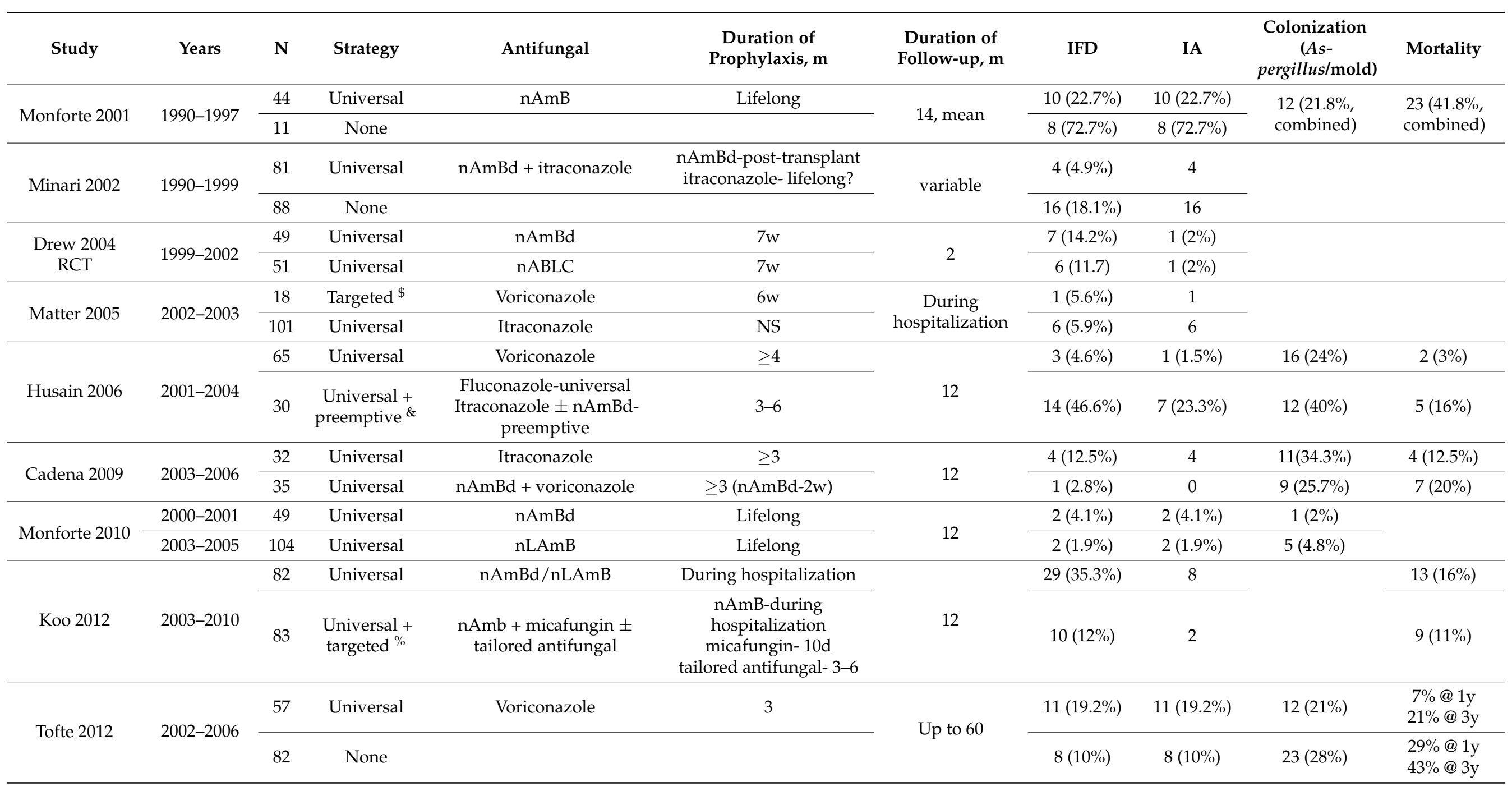


Table 1. Cont.

\begin{tabular}{|c|c|c|c|c|c|c|c|c|c|c|}
\hline Study & Years & $\mathbf{N}$ & Strategy & Antifungal & $\begin{array}{c}\text { Duration of } \\
\text { Prophylaxis, } m\end{array}$ & $\begin{array}{c}\text { Duration of } \\
\text { Follow-up, } \mathrm{m}\end{array}$ & IFD & IA & $\begin{array}{c}\text { Colonization } \\
\text { (As- } \\
\text { pergillus/mold) }\end{array}$ & Mortality \\
\hline \multirow[t]{2}{*}{ Aguilar 2018} & \multirow{2}{*}{ 2005-2008 } & 471 & universal & $\begin{array}{l}\text { Mostly nAmB or } \\
\text { itraconazole }\end{array}$ & Variable & \multirow{2}{*}{48 , median } & $36(7.6 \%)$ & $36(7.6 \%)$ & & \\
\hline & & 429 & Targeted/preemptive & Variable & Variable & & $43(10 \%)$ & $43(10 \%)$ & & \\
\hline Samanta 2020 & 2013-2015 & 144 & Universal & $\begin{array}{l}\text { vuconazole }(+\mathrm{nAmB} \\
\qquad 100 \%)\end{array}$ & 3.4, median & At least 12 & $10(6.9 \%)$ & $3(2 \%)$ & $19(6 \%)$ & $14(10 \%)$ \\
\hline \multirow{2}{*}{$\begin{array}{c}\text { Pennington } \\
2020\end{array}$} & \multirow{2}{*}{ 2002-2017 } & 232 & $\begin{array}{c}\text { Universal + } \\
\text { targeted }\end{array}$ & Variable & Variable & \multirow{2}{*}{12} & $\begin{array}{c}14.94 \% \\
\text { (adjusted) }\end{array}$ & & & $\begin{array}{c}8.36 \% \\
\text { (adjusted) }\end{array}$ \\
\hline & & 232 & none & & & & $\begin{array}{c}22.37 \% \\
\text { (adjusted) }\end{array}$ & & & $\begin{array}{c}19.49 \% \\
\text { (adjusted) }\end{array}$ \\
\hline
\end{tabular}

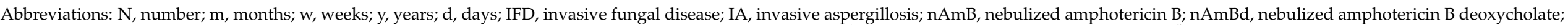

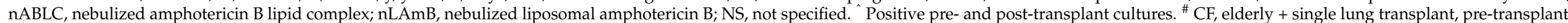

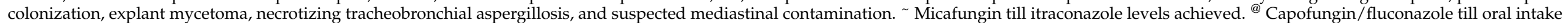

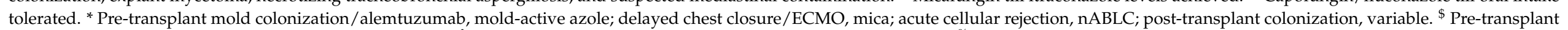
Aspergillus colonization or unexplained perioperative fever. ${ }^{\circ}$ Pre- or post-transplant Aspergillus colonization (except A. niger). ${ }^{\%}$ Positive perioperative culture (mold or yeast) 
The cumulative incidence of IFD among 3561 patients on universal prophylaxis was 0.099 (95\% CI 0.074-0.132, I $\mathrm{I}^{2} 83.9 \%$ ), whereas the cumulative incidence of invasive aspergillosis among 3329 patients was $0.063\left(95 \%\right.$ CI $\left.0.047-0.084, \mathrm{I}^{2} 68 \%\right)$. In studies assessing preemptive treatment, the cumulative incidence of IFD was 0.121 (95\% CI $0.035-0.345, \mathrm{I}^{2} 90.5 \%$ ), and the cumulative incidence of invasive aspergillosis was 0.097 (95\% CI 0.044-0.199, $\mathrm{I}^{2} 67.8 \%$ ). No comparative analysis yielded significant results in favor of any preventive strategy. Five studies compared universal prophylaxis with no prophylaxis [34,56-59]. Of 466 patients on universal prophylaxis, 60 developed IFD compared to 87 of 426 patients that developed IFD without prophylaxis (OR 0.37, 95\% CI 0.13-1.09, I² 78\%, Figure 2A). The odds ratio for invasive aspergillosis in patients on universal prophylaxis compared to no prophylaxis was 0.41 (95\% CI 0.06-2.56, I $\mathrm{I}^{2} 86 \%$, Figure 2B). Only two studies compared universal prophylaxis with preemptive treatment $[13,16]$. Among patients on universal prophylaxis, $39 / 536$ developed IFD compared to $57 / 459$ on preemptive treatment (OR 0.22, $95 \%$ CI $0.02-2.81, \mathrm{I}^{2} 92 \%$, Figure $3 \mathrm{~A}$ ), and 37/536 compared to 50/459 developed invasive aspergillosis (OR 0.24, 95\% CI 0.02-3.27, $\mathrm{I}^{2} 83 \%$, Figure 3B). When comparing universal prophylaxis to either targeted prophylaxis or preemptive treatment, we identified four studies $[10,13,16,60]$ and found no significant difference between the strategies (OR for IFD $0.66,95 \%$ CI $0.14-3.06, I^{2}$ 90\%). Since only 13 studies included data on mortality and studies differed in the time point on which mortality was reported, we could not compile the data.
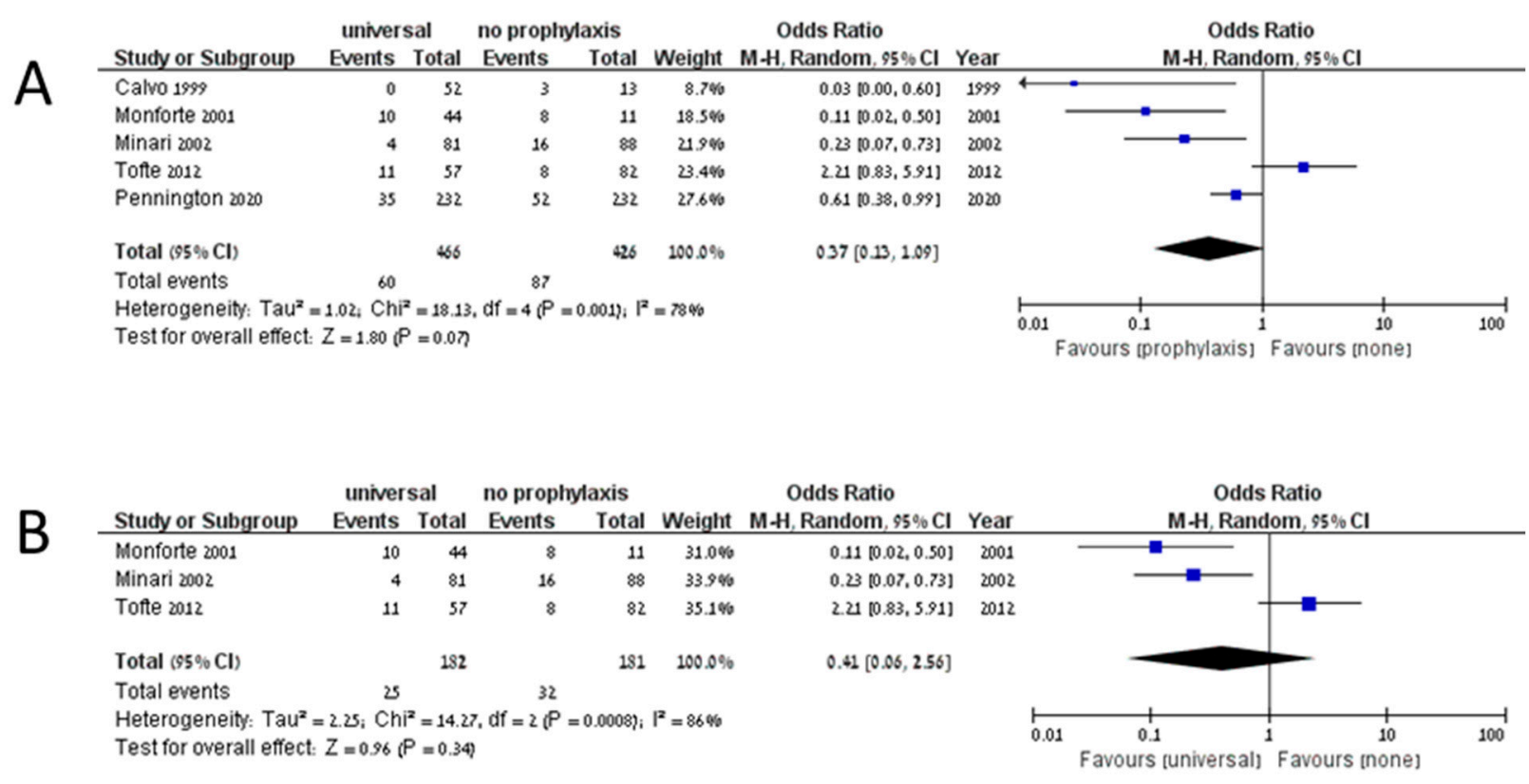

Figure 2. Invasive fungal disease (A) and invasive aspergillosis (B) in studies comparing universal prophylaxis and no prophylaxis.

As shown in the analyses above, no prevention strategy is superior to another. Most available data are derived from small single-center, single-arm studies, explaining the very high heterogeneity observed. Only the analysis comparing universal prophylaxis to no prophylaxis almost reached statistical significance (OR 0.37, 95\% CI 0.13-1.09). This observation is in agreement with common practice in which a preventive strategy is implemented.

Three systematic reviews and meta-analyses have been published to date on this subject [64-66]. Two of the systematic reviews reached a similar conclusion. However, one systematic review concluded that universal prophylaxis is superior [66]. This systematic review included fewer studies. The studies were not as recent as the studies included here (considering that two of the largest series have only recently been published $[8,16])$. 
In this systematic review, universal prophylaxis was compared to all other strategies combined (targeted prophylaxis, preemptive treatment, and no prophylaxis). Nevertheless, we believe that no prophylaxis (which is not routinely practiced) cannot be grouped with other preventive strategies. Therefore, universal prophylaxis's superiority should not be inferred from the systematic review published by Pilarczyk et al. [66].
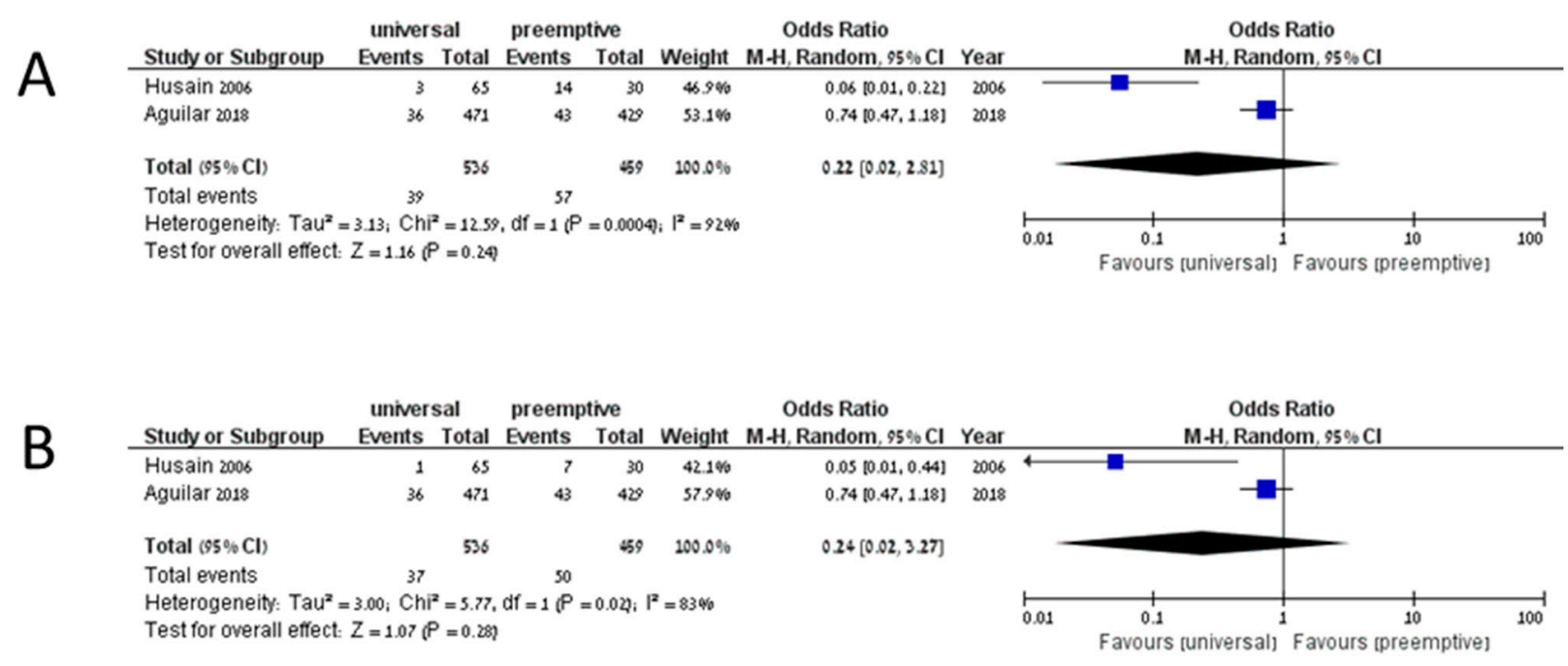

Figure 3. Invasive fungal disease (A) and invasive aspergillosis (B) in studies comparing universal prophylaxis and preemptive treatment.

\subsection{Choice of Drug}

Both mold-active azoles and $\mathrm{nAmB}$ preparations have been used for the prevention of IFD in LTRs. However, studies directly comparing different drugs and using the same prevention strategy are lacking. Two studies, of which one was a randomized controlled trial, compared universal prophylaxis with $\mathrm{nAmBd}$ to nebulized lipid formulations of AmB $[61,63]$. Combined results demonstrated no difference in risk for IFD (OR 1.43 95\% CI $0.52-3.93, \mathrm{I}^{2} 0 \%$ ). A small study compared universal prophylaxis with itraconazole to voriconazole and demonstrated a nonsignificant trend towards a better efficacy with voriconazole [62]. This could possibly be secondary to the inferior pharmacokineticpharmacodynamic profile of itraconazole. With the advent of newer mold-active azoles, itraconazole has fallen out of favor. A recently published trial on 300 LTRs demonstrated a similar efficacy of voriconazole and isavuconazole in terms of preventing IFD [38]. In summary, it seems that both $\mathrm{nAmB}$ and mold-active azoles are adequate agents for universal prophylaxis. As $\mathrm{nAmB}$ has not been evaluated for targeted prophylaxis or preemptive treatment, it should not be used for these indications.

\subsection{Duration}

The duration of antifungal treatment in studies evaluating universal prophylaxis ranged from only during the initial hospitalization $[10,44]$ to lifelong prophylaxis $[50,63]$. Since most studies gave prophylactic antifungals for up to six months, coinciding with the highest risk for IFD [4,16], it seems reasonable to limit universal prophylaxis to that period. Studies assessing preemptive treatment administered antifungals for $3-6$ months $[13,53,54]$. Taking this into account, together with the recommended treatment duration for invasive aspergillosis [27], a treatment duration of approximately three months is suggested for preemptive treatment. 


\subsection{Toxicity}

The use of $\mathrm{nAmB}$ preparations is associated with respiratory side effects, such as a cough, shortness of breath, and bronchospasm, and gastrointestinal side effects, mainly nausea and vomiting. One randomized trial that compared $\mathrm{nAmBd}$ to a nebulized amphotericin B lipid complex (nABLC) showed the significantly better tolerability of nABLC [61]. Nonetheless, the discontinuation of prophylaxis due to side effects did not differ between the two groups, although the study was underpowered for that. When combining the results with a second study that compared prophylaxis with nAmBd to nebulized liposomal amphotericin B (nLAmB) [63], there was no difference in the rate of discontinuation due to side effects (OR 1.88 95\% CI 0.61-5.84).

Mold-active azoles, mainly itraconazole and voriconazole, are associated with numerous side effects and drug-drug interactions [27]. Azoles can cause gastrointestinal intolerance, hepatotoxicity, neurotoxicity, and prolongation of the QT interval, although the probability varies which each drug. Itraconazole exhibits significant variation in absorption, and its most problematic side effect is gastrointestinal intolerance. The main side effects of voriconazole and limiting its use are significant hepatotoxicity, visual disturbances, and numerous drug-drug interactions. Long-term treatment is also associated with an increased risk of skin cancer [27]. A retrospective study on 193 LTRs from Mayo Clinic, Rochester, found that $68.8 \%$ of patients on voriconazole prophylaxis discontinued treatment. In over half of the cases, it was due to side effects or intolerance. Additionally, $61.8 \%$ of patients on itraconazole prophylaxis discontinued treatment, most commonly due to malabsorption $(15.7 \%)$ and suspected breakthrough infection (10.2\%). Contrarily, only $18.3 \%$ of patients on posaconazole prophylaxis had to discontinue treatment [39]. Another recently published study found voriconazole and isavuconazole prophylaxis to be equally effective, although the discontinuation rate was significantly higher for voriconazole ( $36 \%$ vs. $11 \%$ ), mainly due to hepatotoxicity [38]. The drug toxicities of commonly used antifungals are summarized in Table 2.

Table 2. Toxicities of antifungals used for prophylaxis and preemptive treatment.

\begin{tabular}{|c|c|c|}
\hline Drug & Short-Term Toxicity & Long-Term Toxicity \\
\hline \multirow[t]{2}{*}{ Nebulized Amphotericin B } & Respiratory-cough, shortness of breath, bronchospasm & $\begin{array}{l}\text { Damage to surfactant causing } \\
\text { deterioration in pulmonary } \\
\text { function (suspected) }\end{array}$ \\
\hline & GI-nausea, vomiting & \\
\hline \multirow{5}{*}{$\begin{array}{c}\text { Azoles } \\
\text { Itraconazole }\end{array}$} & AKI secondary to cyclodextrin in IV formulation (suspected) & Neurologic-peripheral neuropathy \\
\hline & DDI-CYP3A4 (inhibitor + substrate), Pgp (inhibitor) & \\
\hline & GI-nausea, vomiting (most) & \\
\hline & Hepatotoxicity & \\
\hline & Prolongation of QT interval & \\
\hline \multirow{7}{*}{ Voriconazole } & AKI secondary to cyclodextrin in IV formulation (suspected) & Periostitis \\
\hline & $\begin{array}{l}\text { DDI-CYP2C19 (inhibitor + substrate), } \\
\text { CYP3A4 (inhibitor + substrate) }\end{array}$ & Peripheral neuropathy \\
\hline & Neurologic-visual disturbances, hallucinations & Alopecia \\
\hline & GI-nausea, vomiting, diarrhea & Squamous cell carcinoma of the skin \\
\hline & Hepatotoxicity (most) & \\
\hline & Skin-rash, photosensitivity, perioral excoriations & \\
\hline & Prolongation of QT interval & \\
\hline
\end{tabular}


Table 2. Cont

\begin{tabular}{ccc}
\hline Drug & Short-Term Toxicity & Long-Term Toxicity \\
\hline \multirow{3}{*}{ Posaconazole } & AKI secondary to cyclodextrin in IV formulation (suspected) & Not reported \\
\cline { 2 - 3 } & DDI-CYP3A4 (inhibitor) \\
\cline { 2 - 3 } & GI-nausea, vomiting \\
\hline Isavuconazole & Prolongation of QT interval & Not reported \\
\cline { 2 - 3 } & DDI-CYP3A4 (inhibitor + substrate) \\
\hline
\end{tabular}

Abbreviations: GI, gastrointestinal; AKI, acute kidney injury; DDI, drug-drug interactions.

\section{Conclusions}

IFD, most commonly invasive aspergillosis, remains a significant cause of morbidity and mortality among LTRs. Although it seems that a preventive measure is beneficial, current evidence does not support any specific preventive strategy. The strengths and weaknesses of the different strategies are summarized in Table 3. There is also insufficient evidence to endorse the use of one drug over another. After more than two decades of numerous observational studies, it is time we obtain a definitive answer. A multi-center randomized controlled trial is thus urgently needed.

Table 3. Pros and cons of the different prevention strategies.

\begin{tabular}{lcc}
\hline & Pros & Cons \\
\hline Universal prophylaxis & Easy to implement & $\begin{array}{c}\text { Increased antifungal consumption } \\
\text { Drives resistance } \\
\text { Increased toxicity }\end{array}$ \\
& & $\begin{array}{c}\text { Increased drug-drug interactions } \\
\text { Preemptive treatment }\end{array}$ \\
& $\begin{array}{c}\text { Lower antifungal drug } \\
\text { consumption }\end{array}$ & $\begin{array}{c}\text { Requires resources (surveillance } \\
\text { bronchoscopies, short turnaround time } \\
\text { for galactomannan results) }\end{array}$ \\
\hline
\end{tabular}

Author Contributions: R.B., T.M. and S.H. performed the data search and data analyses. R.B. and S.H. drafted the final manuscript. All authors have read and agreed to the published version of the manuscript.

Funding: This study received no funding.

Institutional Review Board Statement: Not applicable.

Informed Consent Statement: Not applicable.

Data Availability Statement: Not applicable.

Conflicts of Interest: S.H. has received grants from Pfizer, Astellas, Cidera, Merck, and Sunovion at the time of submission of the manuscript. R.B. and T.M. report no conflicts of interest.

\section{References}

1. Health Resources and Services Administration. 2018 Annual Report of the U.S. Organ Procurement and Transplantation Network and the Scientific Registry of Transplant Recipients: Transplant Data 1990-2018; Department of Health and Human Services, Health Resources and Services Administration, Healthcare: Rockville, MD, USA, 2018.

2. Iversen, M.; Burton, C.M.; Vand, S.; Skovfoged, L.; Carlsen, J.; Milman, N.; Andersen, C.B.; Rasmussen, M.; Tvede, M. Aspergillus infection in lung transplant patients: Incidence and prognosis. Eur. J. Clin. Microbiol. Infect. Dis. 2007, 26, 879-886. [CrossRef] 
3. Hosseini-Moghaddam, S.M.; Ouédraogo, A.; Naylor, K.L.; Bota, S.E.; Husain, S.; Nash, D.M.; Paterson, J.M. Incidence and outcomes of invasive fungal infection among solid organ transplant recipients: A population-based cohort study. Transpl. Infect. Dis. 2020, 22. [CrossRef] [PubMed]

4. Doligalski, C.T.; Benedict, K.; Cleveland, A.A.; Park, B.; Derado, G.; Pappas, P.G.; Baddley, J.W.; Zaas, D.W.; Harris, M.T.; Alexander, B.D. Epidemiology of invasive mold infections in lung transplant recipients. Am. J. Transplant. 2014, 14, 1328-1333. [CrossRef]

5. Herrera, S.; Davoudi, S.; Farooq, A.; Tikkanen, J.; Foroutan, F.; Kumar, D.; Humar, A.; Rotstein, C.; Singer, L.G.; Keshavjee, S.; et al. Late Onset Invasive Pulmonary Aspergillosis in Lung Transplant Recipients in the Setting of a Targeted Prophylaxis/Preemptive Antifungal Therapy Strategy. Transplantation 2020, 104, 2575-2581. [CrossRef]

6. Arthurs, S.K.; Eid, A.J.; Deziel, P.J.; Marshall, W.F.; Cassivi, S.D.; Walker, R.C.; Razonable, R.R. The impact of invasive fungal diseases on survival after lung transplantation. Clin. Transplant. 2010, 24, 341-348. [CrossRef]

7. Pappas, P.G.; Alexander, B.D.; Andes, D.R.; Hadley, S.; Kauffman, C.A.; Freifeld, A.; Anaissie, E.J.; Brumble, L.M.; Herwaldt, L.; Lto, J.; et al. Invasive fungal infections among organ transplant recipients: Results of the transplant-associated infection surveillance network (Transnet). Clin. Infect. Dis. 2010, 50, 1101-1111. [CrossRef] [PubMed]

8. Baker, A.W.; Maziarz, E.K.; Arnold, C.J.; Johnson, M.D.; Workman, A.D.; Reynolds, J.M.; Perfect, J.R.; Alexander, B.D. Invasive Fungal Infection after Lung Transplantation: Epidemiology in the Setting of Antifungal Prophylaxis. Clin. Infect. Dis. 2020, 70, 30-39. [CrossRef]

9. Van Delden, C.; Stampf, S.; Hirsch, H.H.; Manuel, O.; Meylan, P.; Cusini, A.; Hirzel, C.; Khanna, N.; Weisser, M.; Garzoni, C.; et al. Burden and Timeline of Infectious Diseases in the First Year After Solid Organ Transplantation in the Swiss Transplant Cohort Study. Clin. Infect. Dis. 2020, 71, e159-e169. [CrossRef]

10. Koo, S.; Kubiak, D.W.; Issa, N.C.; Dietzek, A.; Boukedes, S.; Camp, P.C.; Goldberg, H.J.; Baden, L.R.; Fuhlbrigge, A.L.; Marty, F.M. A targeted peritransplant antifungal strategy for the prevention of invasive fungal disease after lung transplantation: A sequential cohort analysis. Transplantation 2012, 94, 281-286. [CrossRef]

11. Silveira, F.P.; Kwak, E.J.; Paterson, D.L.; Pilewski, J.M.; McCurry, K.R.; Husain, S. Post-transplant Colonization with NonAspergillus Molds and Risk of Development of Invasive Fungal Disease in Lung Transplant Recipients. J. Hearth Lung Transplant. 2008, 27, 850-855. [CrossRef] [PubMed]

12. Vazquez, R.; Vazquez-Guillamet, M.C.; Suarez, J.; Mooney, J.; Montoya, J.G.; Dhillon, G.S. Invasive mold infections in lung and heart-lung transplant recipients: Stanford University experience. Transpl. Infect. Dis. 2015, 17, 259-266. [CrossRef]

13. Husain, S.; Paterson, D.L.; Studer, S.; Pilewski, J.; Crespo, M.; Zaldonis, D.; Shutt, K.; Pakstis, D.L.; Zeevi, A.; Johnson, B.; et al. Voriconazole prophylaxis in lung transplant recipients. Am. J. Transplant. 2006, 6, 3008-3016. [CrossRef]

14. Husni, R.N.; Gordon, S.M.; Longworth, D.L.; Arroliga, A.; Stillwell, P.C.; Avery, R.K.; Maurer, J.R.; Mehta, A.; Kirby, T. Cytomegalovirus infection is a risk factor for invasive aspergillosis in lung transplant recipients. Clin. Infect. Dis. 1998, 26, 753-755. [CrossRef]

15. Cahill, B.C.; Hibbs, J.R.; Savik, K.; Juni, B.A.; Dosland, B.M.; Edin-Stibbe, C.; Hertz, M.I. Aspergillus airway colonization and invasive disease after lung transplantation. Chest 1997, 112, 1160-1164. [CrossRef]

16. Aguilar, C.A.; Hamandi, B.; Fegbeutel, C.; Silveira, F.P.; Verschuuren, E.A.; Ussetti, P.; Chin-Hong, P.V.; Sole, A.; Holmes-Liew, C.; Billaud, E.M.; et al. Clinical risk factors for invasive aspergillosis in lung transplant recipients: Results of an international cohort study. J. Hearth Lung Transplant. 2018, 37, 1226-1234. [CrossRef] [PubMed]

17. Gavalda, J.; Len, O.; San Juan, R.; Aguado, J.M.; Fortun, J.; Lumbreras, C.; Moreno, A.; Munoz, P.; Blanes, M.; Ramos, A.; et al. Risk factors for invasive aspergillosis in solid-organ transplant recipients: A case-control study. Clin. Infect. Dis. 2005, 41, 52-59. [CrossRef] [PubMed]

18. Camargo, J.F.; Husain, S. Immune correlates of protection in human invasive aspergillosis. Clin. Infect. Dis. 2014, 59, 569-577. [CrossRef]

19. Husain, S.; Sole, A.; Alexander, B.D.; Aslam, S.; Avery, R.; Benden, C.; Billaud, E.M.; Chambers, D.; Danziger-Isakov, L.; Fedson, S.; et al. The 2015 International Society for Heart and Lung Transplantation Guidelines for the management of fungal infections in mechanical circulatory support and cardiothoracic organ transplant recipients: Executive summary. J. Hearth Lung Transplant. 2016, 35, 261-282. [CrossRef]

20. Solé, A.; Morant, P.; Salavert, M.; Pemán, J.; Morales, P.; Pastor, A.; Lozano, C.; Vicente, R.; Ramos, F.; Blasco, E.; et al. Aspergillus infections in lung transplant recipients: Risk factors and outcome. Clin. Microbiol. Infect. 2005, 11, 359-365. [CrossRef] [PubMed]

21. Luong, M.L.; Chaparro, C.; Stephenson, A.; Rotstein, C.; Singer, L.G.; Waters, V.; Azad, S.; Keshavjee, S.; Tullis, E.; Husain, S. Pretransplant aspergillus colonization of cystic fibrosis patients and the incidence of post-lung transplant invasive aspergillosis. Transplantation 2014, 97, 351-357. [CrossRef]

22. Nunley, D.R.; Ohori, N.P.; Grgurich, W.F.; Iacono, A.T.; Williams, P.A.; Keenan, R.J.; Dauber, J.H. Pulmonary aspergillosis in cystic fibrosis lung transplant recipients. Chest 1998, 114, 1321-1329. [CrossRef] [PubMed]

23. Helmi, M.; Love, R.B.; Welter, D.; Cornwell, R.D.; Meyer, K.C. Aspergillus infection in lung transplant recipients with cystic fibrosis: Risk factors and outcomes comparison to other types of transplant recipients. Chest 2003, 123, 800-808. [CrossRef] 
24. Hoenigl, M.; Prattes, J.; Spiess, B.; Wagner, J.; Prueller, F.; Raggam, R.B.; Posch, V.; Duettmann, W.; Hoenigl, K.; Wölfler, A.; et al. Performance of galactomannan, beta-d-glucan, aspergillus lateral-flow device, conventional culture, and pcr tests with bronchoalveolar lavage fluid for diagnosis of invasive pulmonary aspergillosis. J. Clin. Microbiol. 2014, 52, 2039-2045. [CrossRef]

25. Geltner, C.; Lass-Flörl, C. Invasive pulmonary Aspergillosis in organ transplants-Focus on lung transplants. Respir. Investig. 2016, 54, 76-84. [CrossRef] [PubMed]

26. Avni, T.; Levy, I.; Sprecher, H.; Yahav, D.; Leibovici, L.; Paul, M. Diagnostic accuracy of PCR alone compared to galactomannan in bronchoalveolar lavage fluid for diagnosis of invasive pulmonary aspergillosis: A systematic review. J. Clin. Microbiol. 2012, 50, 3652-3658. [CrossRef] [PubMed]

27. Patterson, T.F.; Thompson, G.R.; Denning, D.W.; Fishman, J.A.; Hadley, S.; Herbrecht, R.; Kontoyiannis, D.P.; Marr, K.A.; Morrison, V.A.; Nguyen, M.H.; et al. Practice Guidelines for the Diagnosis and Management of Aspergillosis: 2016 Update by the Infectious Diseases Society of America. Clin. Infect. Dis. 2016, 63, e1-e60. [CrossRef] [PubMed]

28. Pfeiffer, C.D.; Fine, J.P.; Safdar, N. Diagnosis of invasive aspergillosis using a galactomannan assay: A meta-analysis. Clin. Infect. Dis. 2006, 42, 1417-1427. [CrossRef] [PubMed]

29. Husain, S.; Clancy, C.J.; Nguyen, M.H.; Swartzentruber, S.; Leather, H.; LeMonte, A.M.; Durkin, M.M.; Knox, K.S.; Hage, C.A.; Bentsen, C.; et al. Performance characteristics of the platelia Aspergillus enzyme immunoassay for detection of Aspergillus galactomannan antigen in bronchoalveolar lavage fluid. Clin. Vaccine Immunol. 2008, 15, 1760-1763. [CrossRef] [PubMed]

30. Husain, S.; Paterson, D.L.; Studer, S.M.; Crespo, M.; Pilewski, J.; Durkin, M.; Wheat, J.L.; Johnson, B.; McLaughlin, L.; Bentsen, C.; et al. Aspergillus galactomannan antigen in the bronchoalveolar lavage fluid for the diagnosis of invasive aspergillosis in lung transplant recipients. Transplantation 2007, 83, 1330-1336. [CrossRef] [PubMed]

31. Jenks, J.D.; Prattes, J.; Frank, J.; Spiess, B.; Mehta, S.R.; Boch, T.; Buchheidt, D.; Hoenigl, M. Performance of the Bronchoalveolar Lavage Fluid Aspergillus Galactomannan Lateral Flow Assay With Cube Reader for Diagnosis of Invasive Pulmonary Aspergillosis: A Multicenter Cohort Study. Clin. Infect. Dis. 2020. [CrossRef]

32. Alexander, B.D.; Smith, P.B.; Davis, R.D.; Perfect, J.R.; Reller, L.B. The $(1,3) \beta$-D-glucan test as an aid to early diagnosis of invasive fungal infections following lung transplantation. J. Clin. Microbiol. 2010, 48, 4083-4088. [CrossRef]

33. Bhaskaran, A.; Kabbani, D.; Singer, L.G.; Prochnow, T.; Bhimji, A.; Rotstein, C.; Finkelman, M.A.; Keshavjee, S.; Husain, S. $(1,3) \beta$-D-Glucan in bronchoalveolar lavage of lung transplant recipients for the diagnosis of invasive pulmonary aspergillosis. Med. Mycol. 2017, 55, 173-179. [CrossRef]

34. Pennington, K.M.; Dykhoff, H.J.; Yao, X.; Sangaralingham, L.R.; Shah, N.D.; Peters, S.G.; Barreto, J.N.; Razonable, R.R.; Kennedy, C.C. The Impact of Antifungal Prophylaxis in Lung Transplant Recipients. Ann. Am. Thorac. Soc. 2020. [CrossRef]

35. Neoh, C.F.; Snell, G.I.; Kotsimbos, T.; Levvey, B.; Morrissey, C.O.; Slavin, M.A.; Stewart, K.; Kong, D.C.M. Antifungal prophylaxis in lung transplantation-a world-wide survey. Am. J. Transplant. 2011, 11, 361-366. [CrossRef]

36. He, S.Y.; Makhzoumi, Z.H.; Singer, J.P.; Chin-Hong, P.V.; Arron, S.T. Practice variation in Aspergillus prophylaxis and treatment among lung transplant centers: A national survey. Transpl. Infect. Dis. 2015, 17, 14-20. [CrossRef]

37. Husain, S.; Zaldonis, D.; Kusne, S.; Kwak, E.J.; Paterson, D.L.; McCurry, K.R. Variation in antifungal prophylaxis strategies in lung transplantation. Transpl. Infect. Dis. 2006, 8, 213-218. [CrossRef]

38. Samanta, P.; Clancy, C.J.; Marini, R.V.; Rivosecchi, R.M.; McCreary, E.K.; Shields, R.K.; Falcione, B.A.; Viehman, A.; Sacha, L.; Kwak, E.J.; et al. Isavuconazole Is as Effective as and Better Tolerated Than Voriconazole for Antifungal Prophylaxis in Lung Transplant Recipients. Clin. Infect. Dis. 2020. [CrossRef] [PubMed]

39. Pennington, K.M.; Razonable, R.R.; Peters, S.; Scott, J.P.; Wylam, M.; Daly, R.C.; Kennedy, C.C. Why do lung transplant patients discontinue triazole prophylaxis? Transpl. Infect. Dis. 2019, 21. [CrossRef]

40. Husain, S.; Camargo, J.F. Invasive Aspergillosis in solid-organ transplant recipients: Guidelines from the American Society of Transplantation Infectious Diseases Community of Practice. Clin. Transplant. 2019, 33. [CrossRef] [PubMed]

41. Ullmann, A.J.; Aguado, J.M.; Arikan-Akdagli, S.; Denning, D.W.; Groll, A.H.; Lagrou, K.; Lass-Flörl, C.; Lewis, R.E.; Munoz, P.; Verweij, P.E.; et al. Diagnosis and management of Aspergillus diseases: Executive summary of the 2017 ESCMID-ECMM-ERS guideline. Clin. Microbiol. Infect. 2018, 24, e1-e38. [CrossRef] [PubMed]

42. Palmer, S.M.; Drew, R.H.; Whitehouse, J.D.; Tapson, V.F.; Duane Davis, R.; McConnell, R.R.; Kanj, S.S.; Perfect, J.R. Safety of aerosolized amphotericin B lipid complex in lung transplant recipients. Transplantation 2001, 72, 545-548. [CrossRef] [PubMed]

43. Shitrit, D.; Ollech, J.E.; Ollech, A.; Bakal, I.; Saute, M.; Sahar, G.; Kramer, M.R. Itraconazole prophylaxis in lung transplant recipients receiving tacrolimus (FK 506): Efficacy and drug interaction. J. Hearth Lung Transplant. 2005, 24, 2148-2152. [CrossRef]

44. Lowry, C.M.; Marty, F.M.; Vargas, S.O.; Lee, J.T.; Fiumara, K.; Deykin, A.; Baden, L.R. Safety of aerosolized liposomal versus deoxycholate amphotericin B formulations for prevention of invasive fungal infections following lung transplantation: A retrospective study. Transpl. Infect. Dis. 2007, 9, 121-125. [CrossRef]

45. Borro, J.M.; Solé, A.; de la Torre, M.; Pastor, A.; Fernandez, R.; Saura, A.; Delgado, M.; Monte, E.; Gonzalez, D. Efficiency and Safety of Inhaled Amphotericin B Lipid Complex (Abelcet) in the Prophylaxis of Invasive Fungal Infections Following Lung Transplantation. Transplant. Proc. 2008, 40, 3090-3093. [CrossRef] [PubMed]

46. Hayes, D., Jr.; Ball, A.M.; Mansour, H.M.; Martin, C.A.; Flynn, J.D. Fungal infection in heart-lung transplant recipients receiving single-agent prophylaxis with itraconazole. Exp. Clin. Transplant. 2011, 9, 399-404. 
47. Mitsani, D.; Nguyen, M.H.; Shields, R.K.; Toyoda, Y.; Kwak, E.J.; Silveira, F.P.; Pilewski, J.M.; Crespo, M.M.; Bermudez, C.; Bhama, J.K.; et al. Prospective, observational study of voriconazole therapeutic drug monitoring among lung transplant recipients receiving prophylaxis: Factors impacting levels of and associations between serum troughs, efficacy, and toxicity. Antimicrob. Agents Chemother. 2012, 56, 2371-2377. [CrossRef]

48. Kato, K.; Nagao, M.; Nakano, S.; Yunoki, T.; Hotta, G.; Yamamoto, M.; Matsumura, Y.; Ito, Y.; Takakura, S.; Chen, F.; et al. Itraconazole prophylaxis for invasive Aspergillus infection in lung transplantation. Transpl. Infect. Dis. 2014, 16, 340-343. [CrossRef]

49. Chong, P.P.; Kennedy, C.C.; Hathcock, M.A.; Kremers, W.K.; Razonable, R.R. Epidemiology of invasive fungal infections in lung transplant recipients on long-term azole antifungal prophylaxis. Clin. Transplant. 2015, 29, 311-318. [CrossRef] [PubMed]

50. Peghin, M.; Monforte, V.; Martin-Gomez, M.T.; Ruiz-Camps, I.; Berastegui, C.; Saez, B.; Riera, J.; Ussetti, P.; Solé, J.; Gavaldá, J.; et al. 10 years of prophylaxis with nebulized liposomal amphotericin B and the changing epidemiology of Aspergillus spp. infection in lung transplantation. Transpl. Int. 2016, 29, 51-62. [CrossRef] [PubMed]

51. Stelzer, D.; Weber, A.; Ihle, F.; Matthes, S.; Ceelen, F.; Zimmermann, G.; Kneidinger, N.; Schramm, R.; Winter, H.; Zoller, M.; et al. Posaconazole liquid vs tablet formulation in lung transplant recipients. Mycoses 2018, 61, 186-194. [CrossRef] [PubMed]

52. Eriksson, M.; Lemström, K.; Suojaranta-Ylinen, R.; Martelius, T.; Harjula, A.; Sipponen, J.; Halme, M.; Piilonen, A.; Salmenkivi, K.; Anttila, V.J.; et al. Control of early aspergillus mortality after lung transplantation: Outcome and risk factors. Transplant. Proc. 2010, 42, 4459-4464. [CrossRef]

53. Neoh, C.F.; Snell, G.I.; Levvey, B.; Kotsimbos, T.; Morrissey, C.O.; Slavin, M.A.; Stewart, K.; Kong, D.C.M. Preemptive treatment with voriconazole in lung transplant recipients. Transpl. Infect. Dis. 2013, 15, 344-353. [CrossRef]

54. Hamacher, J.; Spiliopoulos, A.; Kurt, A.M.; Nicod, L.P. Pre-emptive therapy with azoles in lung transplant patients. Eur. Respir. J. 1999, 13, 180-186. [CrossRef]

55. Pinney, M.F.; Rosenberg, A.F.; Hampp, C.; Schain, D.; Akindipe, O.; Baz, M. Invasive fungal infections in lung transplant recipients not receiving routine systemic antifungal prophylaxis: 12-Year experience at a University Lung Transplant Center. Pharmacotherapy 2011, 31, 537-545. [CrossRef] [PubMed]

56. Calvo, V.; Borro, J.M.; Morales, P.; Morcillo, A.; Viccnte, R.; Tarrazona, V. Antifungal prophylaxis during the early postoperative period of lung transplantation. Chest 1999, 115, 1301-1304. [CrossRef] [PubMed]

57. Monforte, V.; Roman, A.; Gavalda, J.; Bravo, C.; Tenorio, L.; Ferrer, A.; Maestre, J.; Morell, F. Nebulized amphotericin B prophylaxis for Aspergillus infection in lung transplantation: Study of risk factors. J. Hearth Lung Transplant. 2001, 20, 1274-1281. [CrossRef]

58. Minari, A.; Husni, R.; Avery, R.K.; Longworth, D.L.; DeCamp, M.; Bertin, M.; Schilz, R.; Smedira, N.; Haug, M.T.; Mehta, A.; et al. The incidence of invasive aspergillosis among solid organ transplant recipients and implications for prophylaxis in lung transplants. Transpl. Infect. Dis. 2002, 4, 195-200. [CrossRef]

59. Tofte, N.; Jensen, C.; Tvede, M.; Andersen, C.B.; Carlsen, J.; Iversen, M. Use of prophylactic voriconazole for three months after lung transplantation does not reduce infection with Aspergillus: A retrospective study of 147 patients. Scand. J. Infect. Dis. 2012, 44, 835-841. [CrossRef]

60. Mattner, F.; Chaberny, I.F.; Weissbrodt, H.; Fischer, S.; Gastmeier, P.; Haubitz, B.; Gottlieb, J.; Mattner, L.; Strueber, M. Surveillance invasiver Fadenpilzmykosen in lungentransplantierten Patienten: Effekt antimykotischer Prophylaxe mit Itraconazol und Voriconazol. Surveillance of invasive mold infections in lung transplant recipients: Effect of antimycotic prophylaxis with itraconazole and voriconazole. Mycoses 2005, 48, 51-55. [CrossRef]

61. Drew, R.H.; Ashley, E.D.; Benjamin, D.K.; Davis, R.D.; Palmer, S.M.; Perfect, J.R. Comparative safety of amphotericin B lipid complex and amphotericin B deoxycholate as aerosolized antifungal prophylaxis in lung-transplant recipients. Transplantation 2004, 77, 232-237. [CrossRef]

62. Cadena, J.; Levine, D.J.; Angel, L.F.; Maxwell, P.R.; Brady, R.; Sanchez, J.F.; Michalek, J.E.; Levine, S.M.; Restrepo, M.I. Antifungal prophylaxis with voriconazole or itraconazole in lung transplant recipients: Hepatotoxicity and effectiveness. Am. J. Transplant. 2009, 9, 2085-2091. [CrossRef] [PubMed]

63. Monforte, V.; Ussetti, P.; Gavaldà, J.; Bravo, C.; Laporta, R.; Len, O.; García-Gallo, C.L.; Tenorio, L.; Solé, J.; Román, A. Feasibility, tolerability, and outcomes of nebulized liposomal amphotericin B for Aspergillus infection prevention in lung transplantation. J. Hearth Lung Transplant. 2010, 29, 523-530. [CrossRef] [PubMed]

64. Pennington, K.M.; Baqir, M.; Erwin, P.J.; Razonable, R.R.; Murad, M.H.; Kennedy, C.C. Antifungal prophylaxis in lung transplant recipients: A systematic review and meta-analysis. Transpl. Infect. Dis. 2020, 22. [CrossRef]

65. Bhaskaran, A.; Mumtaz, K.; Husain, S. Anti-aspergillus prophylaxis in lung transplantation: A systematic review and metaanalysis. Curr. Infect. Dis. Rep. 2013, 15, 514-525. [CrossRef] [PubMed]

66. Pilarczyk, K.; Haake, N.; Heckmann, J.; Carstens, H.; Haneya, A.; Cremer, J.; Jakob, H.; Pizanis, N.; Kamler, M. Is universal antifungal prophylaxis mandatory in adults after lung transplantation? A review and meta-analysis of observational studies. Clin. Transplant. 2016, 30, 1522-1531. [CrossRef] [PubMed] 